\title{
An Interview with Kotaro Suzumura
}

\author{
WalterBossert \\ Department of Economics, University of Montreal \\ and \\ Marc Fleurbaey \\ Woodrow Wilson School, Princeton University
}

This version: June 30, 2014

The interview was conducted on October 4, 2007, during a Workshop associated with the 2007 Condorcet lectures delivered by Kotaro Suzumura on October 4 and 5, 2007 at the University of Caen. It was revised and expanded substantially on the occasion of Bossert's visit to Waseda University, where Suzumura taught social choice theory and public philosophy over six years after his retirement from Hitotsubashi University until the end of March 2014.

Walter Bossert (WB) and Marc Fleurbaey (MF): We would like to know what influences attracted you to economics in general, and social choice theory and welfare economics in particular early on. We understand that, as an undergraduate student, you did not have much exposure to microeconomic theory as we think of it now, much less to social choice theory and welfare economics. How and when did you develop an interest in these topics?

Kotaro Suzumura (KS): My education in economics began at Hitotsubashi University in 1962, which is one of the best national universities in Japan as far as the humanities and social sciences go. It was the good old days, and we were not trained in the way our students are trained nowadays. Many teachers talked more about their own interests rather than teaching standard courses and following a standard curriculum.

I still remember the first day of the class on development economics taught by a senior professor, who I later learned was a famous scholar. It was an extreme example of non-standard education in these days. I was then a third year undergraduate. Without giving even a word of introduction, he turned his back to us and began to draw a colourful picture on the blackboard, which took more than thirty minutes. Students were puzzled and a stir ran through the classroom. When he completed his artistic work, what appeared on the blackboard was Siddhartha Gautama sitting on a lotus calyx. He turned to us and declared that it represented the economic nirvana. Without uttering any further word, he went out of the classroom to take a puff at a pipe. Needless to say, his theatrical performance took me by surprise. I could have enjoyed it if I had not been pressed by the strong innate desire to pursue my own interest in the performance characteristics of democratic methods of decision-making. I was aware that I could not do so without rigorous discipline if I were to aspire for a sensible academic career. Thus, I decided to spend more time in libraries than in classrooms if I found that the class was unlikely to serve to this end. As a consequence, I became more a self-trained scholar through books of my own choice rather than a well-trained scholar. Needless to say, there were several excellent classes, which helped me greatly in my search for scholarly endeavours. I was also fortunate enough to encounter a few excellent books on microeconomics and related disciplines in the library, which I found intellectually fascinating. I recollect that these books included Takashi Negishi's monograph on Price and Allocation Theory, Hukukane Nikaido's textbook on Mathematical Methods of Modern Economics and, above anything else, Kenneth Arrow's monumental treatise on Social Choice and Individual Values. ${ }^{1,2}$ These books became

\footnotetext{
${ }^{1}$ Negishi's book later formed the core of his classic, Negishi (1972), whereas Nikaido's book was subsequently translated by Kazuo Sato into Nikaido (1970). Needless to say, Arrow's treatise is one of the greatest classics in the theory of social choice.

${ }^{2}$ Hukukane Nikaido (1923-2001) used to be a colleague of Michio Morishima (1923-2004) at the Institute for Social and Economic Research, Osaka University. Subsequently, he moved to the Department of Economics, Hitotsubashi University,
} 
my lifelong resources ever since.

WB \& MF: You said you already had a strong innate desire to study the performance characteristics of democratic methods of decision-making. How did you nourish this interest?

KS: It goes a long way back to my high school days in 1960. The Security Treaty between the United States and Japan was signed on September 8, 1951 after Japan gained full sovereignty at the end of the allied occupation. According to this Treaty, Japan granted the United States the territorial means to establish a military presence in the Far East, which provided the initial basis for Japan's security relationship with the United States. It was in 1959 that bilateral talks on revising the 1951 Security Treaty were started, and the new Treaty of Mutual Cooperation and Security was signed on January 19, 1960 in Washington, D. C. When the treaty pact was submitted to the Japanese Diet for ratification, it triggered harsh debates over the Japan-United States security relationship. An extensive effort was made by the leftist opposition to prevent its passage. The crucial step was taken when the House of Representatives finally approved the pact on May 20, 1960. The Socialist Party representatives boycotted the Lower House session, and they tried to prevent the Liberal Democratic Party representatives from entering the chamber. They were removed by the police force, which led to massive demonstrations and rioting by students, trade union activists, and some ordinary citizens. These demonstrations prevented President Dwight Eisenhower's official visit to Japan and resulted in the resignation of Prime Minister Nobusuke Kishi. However, the House of Councillors failed to vote on the issue within the required thirty days after the Lower House approval, and the Treaty pact was passed by default on June 19, 1960.

The 1960 struggle around the Japan-United States Security Treaty made a high school boy wonder about the virtue of democratic methods of decision-making. Both sides of the struggle, viz., the Liberal Democratic Party government and the opposition, issued stern warnings against the imminent danger of the breakdown of democracy. Although both sides were using the same portmanteau catchword of democracy, it was clear that they assigned very different meanings to the term. For an immature high school boy, it was impossible to crystallize an operational definition of democratic methods of decisionmaking. However, even a naïve high school boy could understand the precarious status of Japan after the independence in the midst of a harsh cold war confrontation between the two opposing camps. Thus, the outcome of the Treaty of Mutual Cooperation and Security seemed to be not only a sensible, but also an inevitable choice, but the political manoeuvre used by the Liberal Democratic Party government in their attempt to pass the pact was too hideous to be approved. This led me to think that there are two aspects of the method of decision-making, viz., the final outcome to which it leads, and the procedure through which the final outcome is brought about, which may well lead us into sharply contrasting judgements on the virtue of democracy.

Having these thoughts in mind, I decided to go on to Hitotsubashi University, where the chances seemed high that I could study social sciences capable of shedding some academic light on my own research agenda.

WB \& MF: You have mentioned Arrow's Social Choice and Individual Values as one of the books you had studied for yourself in pursuit of your personal research agenda. How did you come across Arrow's monumental book while you were still an undergraduate student?

KS: My first encounter with Arrow's monograph, and his general impossibility theorem, was almost accidental. When I was a first year undergraduate student, I was assigned to a compulsory class of mathematics taught by a professor who was strongly committed to the leftist cause of the Maoist school. Although the heat of the 1960 Security Treaty Struggle had come to an end long before this time, he agitated us to stand against the Liberal Democratic Party government. He said that we were assured of the credit of his class if only we could read and write an essay on Mao's book. I decided to neglect his class as well as his essay assignment altogether, and spend the time thereby vacated in the library to pursue my own agenda. As a consequence, I was deprived of a chance to study mathematics along a standard curriculum. Thus, all the mathematics I needed in my research on welfare economics and social choice theory were acquired from reading mathematical books of my own choice.

When I became a third year undergraduate student, I happened to encounter in the library an article written by the Maoist professor in his early days. His article was about general economic equilibrium and social choice. It was out of curiosity that I tried to skim through his article, and I found a rough description of Arrow's General Impossibility Theorem. I do not remember what the professor was saying

where Suzumura was a third-year graduate student. Thus, he could belatedly but fortunately study mathematical economics under Nikaido's supervision. 
about general economic equilibrium and social choice, but I was sufficiently intrigued by the rough statement of the Arrow theorem itself. I rushed to another bookshelf, and could get hold of Social Choice and Individual Values [Arrow $(1951 ; 1963)]$.

Most of my summer in 1964 was devoted to a lonely struggle with Arrow's classic. Although I was unable to understand the full technical details, I was intoxicated for several weeks to follow by the vistas suddenly opened in front of me. My persistent interest in democratic methods of decision-making, coupled with my encounter with Arrow's monograph, led me to pursue the research agenda suggested by Social Choice and Individual Values. I was keenly aware of my lack of solid mathematical training and logical maturity to engage with this project in depth. However, I was confident that I would come back to Arrow's agenda sooner or later.

WB \& MF: What about welfare economics? How did you come to be interested in the normative side of microeconomic theory?

KS: I was aware of the brief history of welfare economics through my reading of Chapter VIII of Paul Samuelson's Foundations of Economic Analysis [Samuelson (1947)]. It was a great reading overall, but it was occasionally too cryptic and terse for a beginner to appreciate. I also read Edward Mishan's "A Survey of Welfare Economics, 1939-1959" [Mishan (1960)], which was useful for the purpose of knowing what had been done at the frontier of welfare economics over the past 20 years. However, I found it disappointing that Mishan had to declare as follows: "While it continues to fascinate many, welfare economics does not appear at any time to have wholly engaged the labours of any one economist. It is a subject which, apparently, one dabbles in for a while, leaves and, perhaps, returns to later in response to a troubled conscience - which goes some way to explain why, more than other branches of economics, it suffers from an unevenness in its development, a lack of homogeneity in its treatment and, until very recently, a distressing disconnectedness between its parts."

I was fortunate enough to have had an opportunity to tackle Arthur Pigou's classic, The Economics of Welfare [Pigou (1920)] around this time. It was Professor Yuichi Shionoya who taught us a course on the Economics of Planning. As a matter of fact, it was not about the Economics of Planning at all; it was a class devoted to a detailed commentary on Pigou's classic. Seizing this opportunity, I read the fourth edition of The Economics of Welfare in the English original. Although I found the structure of this book somewhat disorderly, I was fascinated with his Preface to the Third Edition (1928) which goes as follows: "The complicated analyses which economists endeavour to carry through are not mere gymnastic. They are instruments for the bettering of human life. The misery and squalor that surround us, the injurious luxury of some wealthy families, the terrible uncertainty overshadowing many families of the poor - these are evils too plain to be ignored. By the knowledge that our science seeks it is possible that they may be restrained. Out of the darkness light! To search for it is the task, to find it perhaps the prize, which the 'dismal science of Political Economy' offers to those who face the discipline." The founder's declaration to this effect strongly encouraged me to pursue the path he had cultivated. However, I was also embarrassed by the deep cleavage in between Pigou's moving passion for the cause of welfare economics, on the one hand, and Mishan's derisive comments on the state of welfare economics as of the end of the 1950s, on the other. My interest in welfare economics started from the desire to find a way to fill in this deep cleavage.

WB \& MF: We understood that your interest in social choice theory and welfare economics started with your reading of Arrow, Samuelson, Mishan, and Pigou. Are there any Japanese economists who exerted influence on you in this arena?

KS: Among the Japanese scholars active at the time, there were two who made seminal contributions to our subject, viz., Ken-Ichi Inada (1925-2002) and Yasusuke Murakami (1931-1993). However, they were teaching at different universities (Inada was affiliated with Tokyo Metropolitan University before joining the Institute for Social and Economic Research, Osaka University, and Murakami was teaching at the University of Tokyo). It was not customary in Japan around that time to visit scholars in other universities to ask for guidance and instruction. I found their papers in Econometrica and struggled to understand them. Again, my self-education was quite sporadic and accidental. It was much later that I had personal contact with Inada and Murakami, but they had already lost their research interest in our subject and washed their hands of the business.

After I became aware of the research field of social choice theory through Arrow's classic, the next stage of my self-education in this arena was predominantly through Amartya Sen's wonderful book, Collective Choice and Social Welfare [Sen (1970a)]. His book was not only readable due to his excellent skill of exposition, but also deeply insightful and rich in economic and philosophical contents. As a matter 
of fact, I had the great fortune to hear his presentation at the Far Eastern Meeting of the Econometric Society, which was held in 1968. ${ }^{3}$ The site of the Far Eastern Meeting in the 1960s was always in Tokyo, and Sen's fascinating presentation was on an early version of his justly famous Impossibility of a Paretian Liberal [Sen (1970)]. Inada was the pre-assigned discussant.

WB \& MF: You more or less suggested that your interest in welfare economics and social choice theory was almost accidental, but maybe you already had some orientation towards that kind of issue rather than other issues in economics. Would you give us an idea of the intellectual curiosity, which pushed you towards this direction? Could it be your family background or any other kind of general cultural background?

KS: There are two background reasons for my interest in welfare economics and social choice theory. One of the reasons is straightforwardly connected with the contrast between the two rival economic regimes, viz., the capitalist regime and the socialist regime, whereas the other reason is deeply rooted in the traditional social and economic norms and conventions in Japan, which were starkly constraining us even in the postwar period at least up until the mid-1960s. Let me briefly explain these two reasons one by one.

As I have already explained, Japan regained full sovereignty at the end of the allied occupation. It was in the midst of the harsh cold war confrontation between the opposing regimes. The 1960 Security Treaty Struggle could be understood only by taking the cold war confrontation into consideration. During my first year undergraduate days, I became aware that there was a serious controversy in the 1930s on the rational workability of the socialist regime vis-à-vis the capitalist regime, viz., the Economic Planning Controversy. The functioning of the capitalist regime, which once seemed to lead the free market economies to everlasting prosperity, suddenly became seriously doubtful in view of the New York stock market collapse in 1929 and subsequent worldwide depression, whereas the socialist regime, which was born by the Russian Revolution in 1917, seemed to have circumvented its initial vulnerability and began to grow into the sustainable alternative to the capitalist regime. The controversy was not about the de facto workability of these rival regimes; it was about the rational workability of these rival regimes. The salient players of this controversy were Oscar Lange and Friedrich Hayek, and the crucial point of controversy could be succinctly summarized as follows: Can there be an economic regime that exhibits a satisfactory performance with respect to the list of performance characteristics such as (1) the efficiency of outcomes thereby generated, (2) the compatibility with the respect for a democratic procedure of decision-making and that for individual liberty, and (3) the efficiency in the use of private information for the sake of seeking public objectives? If the answer to this fundamental question is in the affirmative, a further question naturally suggests itself: Can the capitalist regime and/or the socialist regime qualify as an eligible economic regime? In my view, the Economic Planning Controversy in the 1930s already identified many questions to be pursued by welfare economics and social choice theory even though in a crude and informal way. ${ }^{4,5}$ It was this recognition that pushed me towards the study of welfare economics and social choice theory, where the economic regimes are treated, not as historically given constants, but as variables to be designed and implemented.

The other background of my initial interest in welfare economics and social choice theory is firmly rooted in my personal desires in life. Let me explain. Immediately after World War II, the Occupation Authorities adopted many measures in pursuit of the economic democratization of Japan. Among the notable examples of these measures were the Land Reform, which focused on the creation of many owner farmers by facilitating the transfer of farm lands from the absentee landlords to the tenant farmers, the Dissolution of the Zaibatsu, ${ }^{6}$ and the transplantation from the United States to the Japanese soil of the first ever Anti-Monopoly Law. It is true that these so-called Postwar Economic Reforms had a great impact on the society and economy of Japan, but there were deeply seeded morals and conventions that remained almost intact at least until the mid-1960s. I was the only son of a family that was running a small-scale ceramic production/wholesale business. That almost inevitably implied that there was no other way for me than to succeed my father's business and stay in the small hometown throughout my life. Even the choice of higher education was strictly geared towards the usefulness of the study for my future

\footnotetext{
${ }^{3}$ The Far Eastern Meeting of the Econometric Society in the 1960s was started by Michio Morishima, but it was soon discontinued. After a long and big sleep, it resurged in 1987. It was Suzumura who played a crucial role in its revival. See Suzumura (1999a) for the history of the Far Eastern Meeting of the Econometric Society.

${ }^{4}$ Observe that Suzumura's Introduction to Arrow, Sen, and Suzumura (2002) used the Economic Planning Controversy as the basic frame of reference in order to give a clear structure to the multifaceted developments of the theory of social choice.

${ }^{5}$ The basic reference to the Economic Planning Controversy is Hayek (1935).

${ }^{6} \mathrm{~A}$ zaibatsu is a family-dominated financial combine that supposedly exerted strong controls over the Japanese economy in the prewar period.
} 
activities as the helmsman of our family business. As a compromise, I chose Hitotsubashi University so as to study social sciences. Even then, I had to use some tricky arguments to persuade my father and secure this temporary port of refuge. I was keenly aware that the livelihoods of not only my family, but also some of my relatives depended on my personal decision, and I was bitterly reminded of the observation by Ralph W. Emerson: "We do not make a world of our own, but fall into institutions already made, and have to accommodate ourselves to them to be useful at all." You presumably understand that I felt greatly enlightened by the recognition that the study of welfare economics and social choice theory defies the traditional view and treats institutions as variables to be designed and implemented.

WB \& MF: At some point there seemed to be a danger that we may have lost you to a different career altogether - and we are very happy we didn't, of course. You were a quite accomplished Kabuki actor once, weren't you?

KS: That is an extreme exaggeration. I certainly was not an accomplished Kabuki actor at all. There was a student club at Hitotsubashi University devoted to the study of this traditional performing art. Members of the club gathered together and studied the history, the scenario, and the performance of this magnificent art; we also paid frequent visits to the Kabuki Theater in East Ginza and watched fascinating performances of great actors. Needless to say, we could only afford the cheapest possible seats on the highest floor of the theater. If you study performing arts deeply enough in theory as well as in action, you are naturally led to aspire for the active participation in a Kabuki play. At the time, it was not too difficult to get in touch with young and rising Kabuki actors and ask for their guidance. The more we learned and understood how to perform, the more ambitious we became to the extent of aspiring to put our performance on the stage. We had chosen one scenario and I was assigned to play the main character, viz., a young prince who was about to assume the office of shogun in the Kamakura shogunate, but he was destined to be assassinated. This bold attempt simply collapsed for two reasons. The first reason was that it soon became clear that we could not afford to rent gorgeous Kabuki costumes. The second reason was my height; I was simply too tall for a Kabuki actor. There were scenes in which I had to ride on a horse, but the horse itself had to be played by two other actors, one for the front part of the horse and the other for the rear part. The rider was to sit on their joined arms but, in my case, my feet were still in contact with the ground, which would have turned a tragedy into a comedy. Thus, my career as a Kabuki actor ended before it actually got off the ground.

WB \& MF: Let us now turn to your work on welfare economics and social choice theory. Your work on non-welfarist approaches to social choice has been extremely influential over the years. Would you sketch your position in the welfarism versus non-welfarism debate and the role of your contribution in this area? Related to this, where do you stand with regard to the issue of consequentialism versus nonconsequentialism?

KS: As Arrow has acutely observed, "[e]conomic or any other social policy has consequences for the many and diverse individuals who make up the society or economy. It has been taken for granted in virtually all economic policy discussions since the time of Adam Smith, if not before, that alternative policies should be judged on the basis of their consequences for individuals [Arrow (1987, p.124)]." However, the convention of judging the goodness or badness of economic policies on the exclusive basis of their consequences for individuals seems to be open to criticism for at least three reasons.

In the first place, as Aristotle wrote in his Nicomachean Ethics, "[q]uite often good things have hurtful consequences. There are instances of men who have been ruined by their money or killed by their courage." Likewise, Goethe told Johann Peter Eckermann that "[e]verything we do has a result. But that which is right and prudent does not always lead to good, nor the contrary to what is bad." Mark Twain went as far as to claim that "[h]alf of the results of a good intention are evil; half of the results of an evil intention are good." Thus, the consequential outcomes of economic policies seem to fall considerably short of being the sole informational basis for judgements about the goodness or badness of the economic policies in question.

In the second place, I had been keeping my naïve insight nourished during my high school days to the effect that there are two aspects of collective decision-making, viz., the final outcome to which it leads, and the procedure through which the final outcome is brought about. Depending on how we weigh one aspect against the other, we may well be led into contrasting judgements on the virtue of the method of collective decision-making. Given this naïve insight of my own, the exclusive reliance on the consequential outcomes of economic policies in complete neglect of their procedural and/or circumstantial characteristics seemed hard to swallow.

In the third place, I encountered an intriguing passage in Social Choice and Individual Values [Arrow 
(1963, pp.89-90)], which prevented me from accepting Arrow's consequentialist informational basis without reservation: "Up to now, no attempt has been made to find guidance by considering the components of the vector which defines the social state. One especially interesting analysis of this sort considers that, among the variables which taken together define the social state, one is the very process by which the society makes its choice. This is especially important if the mechanism of choice itself has a value to the individuals in the society."

Thus, there seemed to be several reasons to explore the possibility of supplementing the consequentialist approach in welfare economics and social choice theory by bringing in non-consequentialist considerations such as the procedures of choice and the potential opportunities of choice. Making the best use of Arrow's insightful suggestion and following Sen's pioneering attempts in the similar spirit, my own work in this arena focused on the contrast between consequentialism and non-consequentialism in general, and the axiomatic characterization of these sharply contrasting approaches in particular in collaboration with Yongsheng Xu [Suzumura (1999, 2000); Suzumura and Xu (2001, 2003, 2004)].

\section{WB \& MF: What about the contrast between welfarism and non-welfarism?}

KS: As a matter of fact, the main line of research in welfare economics and social choice theory led to the further sophistication of the consequentialist informational basis. Instead of supplementing the consequentialist informational basis by means of non-consequentialist considerations, the first point of departure was to ask how the consequences within the consequentialist approach should be captured. If we are ready to describe the consequences of an economic policy by means of the individual utilities or welfares thereby generated, we are moving towards the branch of welfarist-consequentialism, or welfarism for short. If, on the other hand, we ask for additional information other than individual utilities or welfares in the description of consequences, we are moving towards the branch of non-welfarist-consequentialism, or non-welfarism for short. Most, if not all, work in social choice theory tended to elaborate on the welfaristic basis by imposing an additional requirement of ordinal and interpersonally non-comparable utilities or welfares. It is true that this elaborated informational basis was the natural successor of the ordinalist revolution of microeconomic theory in the 1930s, on the one hand, and the Robbinsian criticism [Robbins (1932)] of the Benthamite-Pigovian tradition of cardinal and interpersonally comparable individual utilities, on the other. In my perception, Arrow succeeded this informational basis in Social Choice and Individual Values and his General Impossibility Theorem for the sake of exposing the poverty of welfarism in this arena.

\section{WB \& MF: How did Sen influence you on the issue of welfarism versus non-welfarism?}

KS: My interest in this issue began with the theory of individual libertarian rights, which was introduced into social choice theory by Sen's justly famous Impossibility of a Paretian Liberal. ${ }^{7,8}$ Sen introduced individual libertarian rights as a vehicle by means of which he could expose the conflict between welfarism in the weak form of the Pareto principle and non-welfarism in the form of the social respect for individual libertarian rights. Given the predominance of the welfaristic approach within the "new" welfare economics and social choice theory, Sen's liberal paradox to the effect that there is no social decision rule that makes the Pareto principle compatible with the social respect for individual libertarian rights caused a great stir in the profession. It was hard to deprive the Pareto principle of its sacrosanct status, whereas giving up the social respect for individual libertarian rights made me uneasy to say the least. I should also add that Sen's liberal paradox reminded me of an observation by Isaiah Berlin [Berlin (1958, pp.15 - 16)] to the effect that "the connexion between democracy and individual liberty is a good deal more tenuous than it seemed to many advocates of both. The desire to be governed by myself, or at any rate to participate in the process by which my life is to be controlled, may be as deep a wish as that of a free area for action, and perhaps historically older. But it is not a desire for the same thing. So different is it, indeed, as to have led in the end to the great clash of ideologies that dominates our world." I owe my interest in the issue of welfarism versus non-welfarism to Sen to the deepest extent.

\footnotetext{
${ }^{7}$ See Sen $(1970 ; 1970 a$, Chapter $6 * ; 1992)$.

${ }^{8}$ When Arrow first presented his General Impossibility Theorem in the Cleveland Meeting of the Econometric Society held in 1949, there was a contentious Canadian political economist among the audience by the name of David McCord Wright. He harshly criticized Arrow and his theorem, because Arrow did not include the respect for individual liberty among the axioms to be satisfied by the Arrow social welfare function. When Suzumura read this episode in Jerry Kelly's (1987) "An Interview with Kenneth Arrow," he asked Arrow what was his spontaneous response to Wright's criticism. Although Arrow didn't remember his initial response, he could have answered Wright's criticism simply by saying: "Give me your definition of individual liberty in the form of an axiom, then the augmented set of axioms would be all the more inconsistent." Nevertheless, the fact is that nobody actually tried to formulate the concept of individual liberty until Sen's paper [Sen (1970)] was published in the Journal of Political Economy more than 20 years later.
} 
A disclaimer on the issue of welfarism versus non-welfarism and that of consequentialism versus nonconsequentialism may be in order. To begin with, although the exclusive reliance on welfare information may well be held responsible for the poverty of normative evaluations, it should not be construed to mean that we should replace the welfaristic informational basis with the non-welfaristic alternative altogether. What it means is that the welfaristic basis should be duly complemented by non-welfaristic information so as to arrive at the proper basis for normative evaluations. Likewise, the role to be played by the non-consequentialist informational basis is not to replace, but to complement the consequentialist informational basis. This is my stance in the issue of welfarism versus non-welfarism as well as in the issue of consequentialism versus non-consequentialism.

WB \& MF: You have mentioned rights as an important topic that got you interested in non-welfarism. Issues such as rights, liberty, freedom of choice and external social norms or external norms in general have been proposed as ingredients that should be added to the more traditional framework of welfare economics and social choice theory. Do you think that large portions of the established framework should be revised in consideration of recent criticisms, for example by Amartya Sen (1993), regarding the internal consistency of choice?

KS: I believe the proper attitude we should take is to complement the traditional approach by accommodating the non-traditional observations rather than to replace this approach with the deontological approach. Indeed, some of my own work in this arena is an attempt to verify the real need for revising the traditional approach in view of the proposed criticisms. If we revise and/or expand the traditional approach appropriately, we may be able to combine seemingly conflicting considerations into the extended approach, thereby enriching the reach of the traditional approach. I would like to be careful not to jump from the standard approach to the non-standard approach too casually. In this sense, I am in full accordance with John Hicks [Hicks (1981, pp.139-140)] who declared that "I have accordingly no intention, in abandoning Economic Welfarism, of falling into the 'fiat libertas, ruat caelum' which some latter-day liberals seem to see as the only alternative. What I do maintain is that the liberal goods are goods; that they are values which, however, must be weighed up against other values. The freedom and justice that are possible of attainment are not the same in all societies, at all times, and in all places; they are themselves conditioned by external environment, and (in the short period at least) by what has occurred in the past. Yet we can recognise these limitations, and still feel that these ends are worthier ends than those which are represented in a production index. It is better to think of economic activity as means to these ends, than as means to different ends, which are entirely its own."

Personally, I would like to accommodate such factors as procedures for making the social choice, opportunities that lie behind the final social choice, and similar non-standard considerations. In so doing, I would like to resist the temptation to pretend that such an accommodation exercise can be conducted by simply expanding the concept of social states. To illustrate my point, consider how we should accommodate the procedural aspect of social choice into the consequentialist framework of social choice theory. Following Arrow's suggestion, we may want to expand the description of social states, say $x, y$ in the universal set $X$ of narrowly defined social states, by defining the pair $(x, \eta)$ [resp. $(y, \theta)]$ means that the narrowly defined social state $x$ [resp. $y$ ] is brought about through the mediation of the social choice procedure $\eta$ [resp. $\theta$ ]. This can surely be done, but there is no guarantee that the traditional approach can be applied to this expanded conceptual framework. To bring this simple point home, let us describe the social choice procedure in terms of the game form $\eta=\left(N ; \boldsymbol{\Sigma}=\left\{\Sigma_{1}, \Sigma_{2}, \ldots, \Sigma_{n}\right\} ; g\right)$, where $N=\{1,2, \ldots, n\}$ denotes the set of all players, $\Sigma_{i}$ is the set of strategies of the player $i \in N$, and $g$ is the outcome function that maps each and every profile of individual strategies into a narrowly defined social state. Let $S \subseteq X$ be the opportunity set of narrowly defined social states. A narrowly defined social stat $x$ is feasible if and only if we are assured that $x$ belongs to $S$, whereas an extended social state $(x, \eta)$ is feasible if and only if we are assured that $x \in g(\epsilon(\eta, \boldsymbol{R}))$ holds true, where $\epsilon$ is the equilibrium concept that prevails in the society, and $\boldsymbol{R}=\left(R_{1}, R_{2}, \ldots, R_{n}\right)$ is the profile of individual preference orderings on the set $X$ of narrowly defined social states. Thus, just to verify the feasibility of extended social states, we should be provided with the equilibrium concept $E$ prevailing in the society and the profile $\boldsymbol{R}$ of individual preference orderings on the set $X$ of narrowly defined social states. A sharp contrast between the theory based on the conventionally defined social states and that based on the expanded social states is too conspicuous to be overlooked.

WB \& MF: Rights have clearly played a major role throughout your career, and your 1992 Economica paper [Gaertner, Pattanaik, and Suzumura (1992)] had a strong influence on the debates surrounding this subject. Some of our colleagues say that your paper has awakened them from their dogmatic slumber, so it was really a landmark paper. Would you tell us more about how you became interested in this issue, 
how you would summarize the evolution of the debate on rights within social choice theory, and where you see this debate going in the future?

KS: When I first encountered the Impossibility of a Paretian Liberal (IPL), I was strongly impressed by the simple structure Sen used in exposing the logical conflict between the value of democracy in the weak form of the Pareto principle and the value of liberty in the straightforward form of the social respect for individual libertarian rights. On reflection, Arrow's general impossibility theorem seemed to hinge squarely on the requirement of collective rationality and the requirement of informational efficiency, viz., the independence of irrelevant alternatives, both of which are controversial and harshly debated in the literature. In sharp contrast, Sen's $I P L$ does not require both these controversial axioms. As far as we accept Sen's formulation of individual libertarian rights, the IPL seems to have posed a genuine paradox. My early work on the issue of libertarian rights accepted Sen's formulation of rights in terms of the preference-contingent power of individuals to impose the rights-based constraints on the final social choice, and tried to identify a general method of resolving the IPL. One of the proposed resolution schemes, which was christened the Sen-Suzumura resolution scheme by David Austen-Smith [Austen-Smith (1982)], capitalizes on the concept of a liberal individual introduced by Sen [Sen (1976)]. According to Suzumura (2011, p.630), "an individual is liberal if and only if he claims only those parts of his preferences, which are compatible with others' preferences over their respective protected spheres, to be counted in social choice." As Sen (1976) and Suzumura (1978) have shown, there exists a rational social choice procedure, under which the Pareto principle and the social respect for individual libertarian rights in the sense of Sen are logically compatible, if only there exists at least one liberal individual in the society.

I found this possibility theorem particularly satisfactory, as it provided me with an arena where my work on the logical structure of binary relations played an essential role. However, my satisfaction was short-lived, as I soon became rather skeptical about Sen's formulation of individual libertarian rights. Jointly with Wulf Gaertner and Prasanta Pattanaik, I found many instances in which Sen's formulation turned out to be contrary to our intuitive conception of the freedom of choice. Further examination led us to the alternative formulation of individual rights, which is game-theoretic in nature and seems to be better suited to capture the essence of the classical idea of the freedom of choice. Our investigation culminated into a three-author joint article [Gaertner, Pattanaik and Suzumura (1992)] which captures my up-to-date understanding of the concept of individual libertarian rights. In trying to crystallize this alternative approach to individual rights in terms of game forms, we were under strong influence of trailblazers, most notably Robert Nozick (1974) and Robert Sugden (1985).

In order to avoid possible misunderstandings, two caveats may be in order at this juncture. In the first place, our so-called game-form approach is meant to provide an alternative formulation of rights, but there is no claim that this alternative approach is effective in dissipating Sen's IPL altogether. Quite to the contrary, there are many instances where the claim of game-form rights may conflict with the Pareto principle. It is for this reason that we made it clear that our basic concern is the formulation of the notion of individual rights per se, and not the conflict between the requirement of individual rights and that of the weak welfaristic requirement of Pareto optimality. It is our firm belief that the $I P L$ persists under virtually every plausible concept of individual rights that we can think of. In the second place, the notion of game forms per se has very little to do with rights. Our claim is that the best way to capture individual rights is by means of game forms, and that there are numerous game forms having no relevance to the question of rights at all.

WB \& MF: Any thoughts on Gibbard's paradox and its significance that you might want to add?

KS: Allan Gibbard [Gibbard (1974)] made three important contributions to the theory of libertarian rights by taking Sen's formulation of rights for granted. In the first place, he identified what came to be known as the Gibbard paradox to the effect that the conferment of the Sen rights to each and every individual may result in a social preference cycle by itself. In contrast with Sens IPL, the Gibbard paradox has nothing to do with the welfaristic Pareto principle. It is easy to verify that this paradox hinges squarely on the nature of individual preference orderings to the effect that Mr.A wants to match the color of his necktie with that of Ms.B's neckerchief, whereas Ms.B abhors Mr.A's mimicry and would like to differentiate the color of her neckerchief from that of Mr.A's necktie. The convinced libertarian would not require that this pattern of others-oriented individual preference orderings be socially respected, which ushered Gibbard into the crucial concept of unconditional preferences. His second contribution was to show that the IPL tenaciously comes back if we allow individuals to express unconditional preferences only. In the third place, Gibbard (1974, p.397) invented the novel concept of alienable libertarian rights, which might well be traced back to "a strong libertarian tradition of free 
contract," according to which "a person's rights are his to use or bargain away as he sees fit." His great accomplishment was to show that there exists a social choice rule that makes the Pareto principle and the alienable libertarian rights logically compatible. In my perception, Gibbard's multifaceted contribution brought the debates on the IPL to a higher stage by several steps. From the hindsight that the game form approach to rights afforded us, however, the appeal of Gibbard's contribution seems much less than it seemed in those days. In particular, it is clear that Gibbard's paradox is a mirage if we formulate rights as in the theory of game-form rights.

WB \& MF: For more than three decades, you have made many path-breaking contributions to the theory of rational choice, both at the individual and at the collective level. Where do you see this field moving in general? Do you personally have specific ongoing and future projects in this area?

KS: Rationality of choice is a subject that has been central in economics throughout its evolution. According to Andreu Mas-Colell (1982), Paul Samuelson once observed that, even after a hundred years, we would be talking economics in terms of such a concept as rational choice. Just like Samuelson, I am strongly convinced that rational choice is a concept that lies at the core of economic theory in general, and welfare economics and social choice theory in particular. Having said this, I should hasten to add that the concept of rational choice has always been controversial, and will remain so in the future too. My own contributions in the theory of rational choice have focussed on the concept of rationality as rationalizability, which can be traced to Lionel Robbins (1932, p.93): "[T]here is a sense in which the word rationality can be used which renders it legitimate to argue that at least some rationality is assumed before human behaviour has an economic aspect - the sense, namely, in which it is equivalent to 'purposive' ... . ... [T] o say this is not to say in the least that all purposive action is completely consistent."

My own research started within revealed preference theory, which is a theory of rationalizability of consumer's demand behaviour in perfectly competitive markets. Although the seminal contributions in this arena by Paul Samuelson $(1938,1948,1950)$ and Hendrik Houthakker (1950) fascinated me a lot, the fact that it applies only to competitive consumers made me feel that it is still only a partial theory. To bring the theory to its completion, we must go beyond competitive consumers and treat choice functions defined on an arbitrary choice space. Two responses evolved in the literature. The first response was due to Kenneth Arrow (1959) and Amartya Sen (1971), whereas the second response came from Marcel Richter (1966) and Bengt Hansson (1968). Arrow and Sen developed a theory of rationality as rationalizability for a choice function whose domain contains the family of non-empty finite subsets of an arbitrary universal set, whereas Richter and Hansson developed a theory for a choice function whose domain consists of the family of non-empty arbitrary subsets of an arbitrary universal set. It was about this time that I arrived in this field of research. Beginning with two papers, viz., "Rational Choice and Revealed Preference" [Suzumura (1976)] and "Houthakker's Axiom in the Theory of Rational Choice" [Suzumura (1977)], I started my own research on the theory of rationality as rationalizability along the lines of the Richter-Hansson approach.

WB \& MF: On the topic of the rationalizability of choices, one of your fundamental contributions emerged in this context, but it has much more far-reaching implications. We have in mind your generalization of Szpilrajn's (1930) seminal theorem on the extension of binary relations to orderings. ${ }^{9} \mathrm{He}$ proves that transitivity is a sufficient condition for the existence of an ordering extension, but your result goes considerably further - you show that consistency in your sense is a necessary and sufficient condition for the existence of such an extension. Would you briefly outline this remarkable result for us and tell us how you came to think about this issue? What do you see as possible alternative applications and uses of consistency?

KS: It was in the mid-1970s that I developed this concept of consistency while I was a visiting scholar at Cambridge University. I was then pursuing two distinct research projects. One project was on the theory of revealed preference along the lines of Richter and Hansson, whereas the other project was on the theory of libertarian rights along the lines of Sen. Quite unexpectedly, these two seemingly unrelated projects turned out to hinge crucially on the same concept, which I called consistency. ${ }^{10}$ The origin of

\footnotetext{
${ }^{9}$ Let $R$ and $R^{*}$ be two binary relations on the universal set $X . R^{*}$ is said to be an ordering extension of $R$ if we have (i) $R \subseteq R^{*}$, (ii) $P(R) \subseteq P\left(R^{*}\right)$ and (iii) $R^{*}$ is an ordering on $X$, where $P(R)$ [resp. $P\left(R^{*}\right)$ ] is the asymmetric part of $R$ [resp. $\left.R^{*}\right]$.

${ }^{10}$ There are many concepts of consistency in the literature. To avoid confusion, Walter Bossert (2008) coined a new term of Suzumura consistency for the consistency concept introduced by Suzumura (1976a). From this point onward, we will be using this new nomenclature.
} 
this concept can be traced back to Houthakker's (1950) axiom of semi-transitivity, on the one hand, and David Champernowne's (1969) axiom of consistency, on the other.

Houthakker introduced his semi-transitivity axiom with the purpose of strengthening Samuelson's weak axiom and establishing the rationalizability of a demand function by means of a preference ordering. Samuelson (1950) restated Houthakker's axiom and formulated what he called the strong axiom of revealed preference. While I was working on the rationalizability theory along the lines of Richter and Hansson, I encountered an intriguing puzzle. Contrary to Samuelson's scenario, there seemed to exist a grave cleavage between the choice functional counterpart of the semi-transitivity axiom and the choice functional counterpart of the strong axiom, which seemed to disappear for single-valued choice functions. Samuelson's identification of Houthakker's semi-transitivity axiom and his strong axiom was valid in the context of their revealed preference theory for single-valued demand functions. For general choice functions, however, the choice functional counterpart of the semi-transitivity axiom and the choice functional counterpart of the strong axiom are distinct axioms altogether, the former being logically stronger than the latter. Suzumura (1977) showed that a general multi-valued choice function is rationalizable by means of an ordering if and only if it satisfies Houthakker's semi-transitivity axiom formulated by myself.

Champernowne (1969, Chapter 2) introduced a novel concept of consistency, which may be called Champernowne consistency, of preference or probability relations. Let $X$ be the universal set of alternatives and $R$ be a binary relation on $X$. A $t$-tuple of alternatives $\left(x^{1}, x^{2}, \ldots, x^{t}\right)$ in $X$ is a $C$-cycle of order $t$ if and only if

$$
\left(x^{1}, x^{2}\right) \in P(R) \cup N(R),\left(x^{\tau}, x^{\tau+1}\right) \in R(\tau=2,3, \ldots, t-1) \&\left(x^{t}, x^{1}\right) \in R
$$

where $(x, y) \in N(R)$ holds if and only if $(x, y) \notin R$ and $(y, x) \notin R$ hold. $R$ is Champernowne-consistent if and only if there exists no $C$-cycle of any finite order. This concept seemed persuasive, but I found an intriguing puzzle in this arena too. As soon as I encountered this interesting consistency concept, I proved that a binary relation $R$ is Champernowne-consistent if and only if it is transitive. It did not take long before I formulated a new concept of consistency, viz., Suzumura-consistency A $t$-tuple of alternatives $\left(x^{1}, x^{2}, \ldots, x^{t}\right)$ in $X$ is an $S$-cycle of order $t$ if and only if

$$
\left(x^{1}, x^{2}\right) \in P(R),\left(x^{\tau}, x^{\tau+1}\right) \in R(\tau=2,3, \ldots, t-1) \&\left(x^{t}, x^{1}\right) \in R
$$

holds true. $R$ is Suzumura-consistent if and only if there exists no $S$-cycle of any finite order. In view of the unfortunate fate of Champernowne-consistency, I had every reason to be cautious about the properties of Suzumura-consistent binary relations. It turned out that: (i) As in the case of Sen's (1969) concept of quasi-transitivity, Suzumura-consistency lies strictly in between transitivity and acyclicity in logical strength; (ii) The discrepancy between transitivity and Suzumura-consistency disappears if $R$ is complete; (iii) A binary relation $R$ has an ordering extension $R^{*}$ if and only if $R$ is Suzumura-consistent. Needless to say, property (iii) is nothing other than the generalization of Szpilrajn's theorem, which you have already mentioned.

It turns out that my ordering extension theorem is of crucial importance in many distinct contexts. To begin with, my proof that a choice function $C$ is rationalizable by means of a preference ordering if and only if $C$ satisfies Houthakker's axiom depends heavily on the logic of Suzumura-consistency. In the context of the Pareto libertarian paradox, I generalized Sen's concept of a liberal individual that played the role of switching the impossibility theorem into a possibility theorem. In this context as well, it was my ordering extension theorem that proved of essential usefulness in the formulation of a liberal individual. I should also mention the recent concept of the Suzumura-consistent closure of a binary relation introduced by Bossert, Sprumont and Suzumura (2005). The Suzumura-consistent closure $s c(R)$ of a binary relation $R$ is the smallest Suzumura-consistent superset of $R$. It is this concept that enabled us to characterize the novel concept of Suzumura-consistent rationalizability of a general choice function.

I believe that the concept of Suzumura-consistency and the generalized ordering extension theorem will play an essential role in many other fields of individual and social choice including, among others, choice under uncertainty.

WB \& MF: In the early eighties you managed to establish a link between concepts emanating from the theory of fairness, in particular no-envy, and the formal apparatus of social choice theory. How do you view the relation between the various subfields of normative economics such as social choice theory, the theory of fair allocation, welfare economics, inequality and poverty measurement, cost-benefit analysis, and so on? Should we aim at integrating these domains into a unified theory, or should we instead develop specialized subfields independently? 
KS: There was a strong tendency among the advocates of fairness as no-envy approach such as Serge Kolm (1972) and Hal Varian $(1974,1975)$ to emphasize the sharp cleavage between Arrow's social choice theory and their own approach to the extent of losing sight of the possible complementarities between them. One clear instance is the statement by Varian (1975): "[S]ocial decision theory asks for too much out of the [preference aggregation] process in that it asks for an entire ordering of the various social states. ... The original question asked only for a good allocation; there was no requirement to rank all allocations. The fairness criterion in fact limits itself to answering the original question. It is limited in that it gives no indication of the merits of two non-fair allocations, but by restricting itself in this way it allows for a reasonable solution to the original problem." Likewise, Kolm (1996) claimed that "the assumption of a social ordering, as well as the other weaker or alternative assumptions ... are at odds with standard conceptions of equity and justice, and with consequences of rationality in the normal sense of 'for a reason' ... . ... Why would we want to know the 193th best alternative? Only the first best is required for the choice." To put the Arrow social choice theory on the same stage as the Kolm-Varian fairness theory, I invoked the extended sympathy approach suggested by Patrick Suppes (1966) and formalized by Amartya Sen (1970a, Chapter 9*). ${ }^{11}$ I showed in Suzumura (1981) that (i) the logical conflict between no-envy fairness and Pareto efficiency surfaces simply and transparently, and (ii) there exists no generalized social choice rule that satisfies the axiom of fairness extension (FE) and the superset axiom of choice consistency (SUA). ${ }^{12}$ This result is important, as it shows unambiguously that there exists no Arrovian social choice rule that is compatible with no-envy fairness even under the choice-consistency condition that is much weaker than Arrow's axiom of collective rationality. This exercise seems to suggest that there are cases where various subfields of normative economics could be integrated within an extended conceptual framework. However, the area of normative economics is so slippery that we should be careful enough in judging about the pros and cons of this research program.

It is true that the great merit of the axiomatic approach is to enable us to accommodate apparently separate branches into a single axiomatic framework, thereby facilitating crystal-clear and comprehensive analyses with a broader perspective. However, in the process of combining various branches into a single framework of axiomatic analysis, there is a clear danger of falling into the Procrustean trap: We may chip off some rich idiosyncratic features of the branches in question for the sake of making them subsumable into the uniform framework. Another danger is that, after the original branch is laid down on the Procrustean bed, it is all too easy to forget about bringing the results of the axiomatic analysis back to the original context. It is in full awareness of these potential dangers that I am not eager to pursue a premature synthesis of various branches into a single axiomatic framework.

WB \& MF: Your work displays a broad and sustained interest for the conceptual debates about the foundations of welfare analysis, with some predilection for the critical approaches. In your view, how should one think of the interaction between economics and philosophy in this respect? Do you have a favourite theory of social justice?

KS: Concerning your first question, a passage of Georg W. F. Hegel spontaneously comes to my mind: "A further word on the subject of issuing instructions on how the world ought to be: philosophy, at any rate, always comes too late to perform this function. As the thought of the world, it appears only at a time when actuality has gone through its formative process and attained its completed state. This lesson of the concept is necessarily also apparent from history, namely that it is only when actuality has reached maturity that the ideal appears opposite the real and reconstructs this real world, which it has grasped in its substance, in the shape of an intellectual realm. When philosophy paints its grey in grey, a shape of life has grown old, and it cannot be rejuvenated, but only recognized, by the grey in grey of philosophy; the owl of Minerva begins its flight only with the onset of dusk [Hegel (1991, p.23)]."

In my perception, normative economics, which subsumes social choice theory and welfare economics, has two intellectual origins. ${ }^{13}$ The first origin, from which social choice theory was born, may be attributed to the pioneering work of Marie-Jean de Condorcet and Jean-Charles de Borda. Condorcet addressed the mathematical discipline of collective decision-making by means of his analysis of simple

\footnotetext{
${ }^{11}$ The extended sympathy approach will be discussed further in the context of interpersonal comparisons of well-being.

${ }^{12}$ The axiom (FE) requires that the social choice set $C(S)$ should coincide with the fair set $F(S)$, which is defined by the intersection of the Pareto efficient set $E_{f}(S)$ and the no-envy set $E_{q}(S)$, whenever $S$ is such that $F(S)$ is non-empty. The axiom (SUA) is a weak choice-consistency condition to the effect that $\left[S_{1} \subseteq S_{2} \& C\left(S_{2}\right) \subseteq C\left(S_{1}\right)\right]$ implies $C\left(S_{1}\right)=C\left(S_{2}\right)$, which is much weaker than Arrow's collective rationality condition.

${ }^{13}$ According to Suzumura's "Introduction" to Handbook of Social Choice and Welfare, Vol.1 [Arrow, Sen, and Suzumura, eds. (2002, pp.1-32)], "[s]ocial choice theory is concerned with the evaluation of alternative methods of collective decisionmaking, as well as with the logical foundations of welfare economics. In turn, welfare economics is concerned with the critical scrutiny of the performance of actual and/or imaginary economic systems, as well as with the critique, design and implementation of alternative economic policies."
} 
majority voting and related procedures. It was Condorcet who identified the first major paradox in social choice theory, which became widely known under the title of the Condorcet paradox. His contribution seems to have been inspired by an earlier work by Borda, who proposed to the French Academy of Science the rank-order method of decision-making. Two conspicuous features of this phase of social choice theory may deserve emphasis. On the one hand, the informational basis of the methods proposed by Condorcet and Borda is unambiguously welfarist with ordinal and interpersonally non-comparable utilities. On the other hand, the philosophical background of their work can be traced to the intellectual atmosphere of the European Enlightenment with its conspicuous concern about human rights and the reasoned design and implementation of the method of collective decision-making. The second origin of normative economics, from which welfare economics was born, can be attributed to Jeremy Bentham, who was a stark critic of the concept of inviolable natural rights. It was in the context of his harsh criticism on the French "Declaration of the Rights of Man and the Citizen," which was embodied in the French Constitution of 1791, that Bentham wrote the following famous passage: "[N]atural rights is simple nonsense: natural and imprescriptible rights, rhetorical nonsense, - nonsense upon stilts [Bentham $(1789,1843)] . "$ Bentham was a legal philosopher who took recourse to the greatest happiness principle to the effect that the ultimate criterion for judging the goodness of an economic system and/or economic policy is that they bring about the "greatest happiness of the greatest number." This utilitarian criterion of judgment about economic systems and/or economic policies permeated through the work of John Stuart Mill, Alfred Marshall, Francis Edgeworth, and Henry Sidgwick, which served as a natural basis for the synthesis of the long philosophical tradition in England by the hands of Arthur Pigou (1920) in the early twentieth century. Needless to say, the informational basis of this Benthamite tradition is unambiguously welfarist with cardinal and interpersonally unit-comparable utilities.

Thus, the two origins of normative economics are closely related to the philosophical atmosphere of the European Enlightenment, on the one hand, and the English tradition of utilitarianism, on the other. The interface between normative economics and philosophy is indeed deep and wide, and I believe that this interface will prove crucial in the future as well. Amartya Sen has contributed more than anybody else to make us aware of the importance of this interface.

Before answering your second question, let me explain my stance towards various theories of justice. Even if I am a devotee of the theory A of justice as a matter of my personal conviction, this fact does not enable me as a scholar of normative economics to neglect the other theory B of justice altogether if I am not ready to be paternalistic in my normative analysis. As a social scientist, I should explore the logical coherence of the theory $\mathrm{B}$ as well as the implications thereof in various contexts of the design and/or implementation of economic policies and economic systems.

After bringing this point home, however, I have no reason to hide my struggle over many years in the narrowly confined space between the procedural theories of justice and the consequentialist theories of justice. I am unable to become a devout believer in the consequentialist theory of justice pure and simple, forgetting about the legitimacy of the decision-making procedure through which the consequences are brought about. However, I am also unable to be so dogmatic as to neglect the consequences of an economic policy and/or an economic system altogether, and stick to the deontological principle of justice pure and simple. In this context, it is hard for me to resist the temptation to cite a nice passage from Amartya Sen (1970a, p.200): "[W]hile 'pure' systems of collective choice tend to be more appealing for theoretical studies of social decisions, they are often not the most useful systems to study. ... Both from the point of view of institutions as well as that of frameworks of thought, the impure systems would appear to be relevant. ... [W]hile purity is an uncomplicated virtue for olive oil, sea air, and heroines of folk tales, it is not so for systems of collective choice." I have been struggling to find a way to strike a balance between two principles of justice, viz. the procedural principle of justice and the consequentialist principle of justice.

WB \& MF: Would you explain in some more detail how you see the role of the social choice theorist in the debates about social justice? Maybe you also might want to share a few more details regarding your personal theory of justice, even though you don't make use of it directly in your theoretical work.

KS: Let us illustrate my own stance on the role of social choice theorists in this arena. Suppose that I am provided with two principles of justice from outside, say $\omega_{A}$ and $\omega_{B}$. In my view, the due task of the social choice theorist seems to be three-fold. In the first place, it is his task to squeeze out their crucial implications in the critical contexts as a test of their logical coherence and intuitive reasonableness. If one or the other of these principles exposes a disagreeable implication in one of the test fields, his task as a scientist is to advise people to think twice about their blind devotion to such a repugnant principle of justice. Suppose that both $\omega_{A}$ and $\omega_{B}$ do not reveal any repugnant implication in this test. It is his further task to find a set of characterizing axioms for each one of these principles of justice. This is for 
the sake of making the contrast between the rival principles of justice crystal-clear, and assisting the devotees of the rival principles of justice to be aware of the logical foundations of their ethical beliefs. An important further task of social choice theorists is to see if each principle of justice does not create a logical conflict with other basic principles such as the principle of efficiency. Suppose that the rival principles of justice successfully pass this hurdle. In my perception, the social choice theorist is still left with the third task, which is to find a method of combining the rival principles of justice and clarify the logical performance of the compound principle. There are two methods of juxtaposition, viz., the set-theoretic union and the set-theoretic intersection, and there are also two methods of lexicographic combination, viz., $\omega_{A}$ and $\omega_{B}$ second, or the other way round. I myself tried to work out the logical performance of the lexicographic combinations in Suzumura (1983a). The methods of lexicographic combination were further explored by Koichi Tadenuma (2002).

You also asked to further clarify my personal theory of justice. As I said already, I have always been struggling to find a way to strike a balance between two principles of justice, viz., procedural justice and consequentialist justice. It was through my study on the rule-oriented approach to the theory of fair measures and practices of trade among member countries within the GATT/WTO regime, as well as on the design and implementation of the competition law and policy that I reached my current understanding on how to combine these two principles of justice. Let me explain this scenario in the concrete context of competition law and policy.

Suppose that a competitive game is played under the prevailing competition law, which is supposed to implement the ex ante notion of justice. When the dust of competition is off, a competitor, to whom the result of the game turned out to be unfavorable, may cry against the injustice of the competitive outcome. I am unwilling to respond hastily to this cry and revise the ex ante just rule of the game. However, I am also unwilling to reject the discontent player's plea just because he agreed to participate in the competitive game in awareness that it implements the ex ante just rule of the game.

This leads me to the three-stage examination of the justice of the ex ante rule of the game. In the first stage, the defeat of the discontent player may be due to his own mistake in choosing his competitive strategy. In this case, there seems to be no reason to revise the ex ante rule of the game even if we have full sympathy with the plight of the discontent player. In the second stage, his defeat may be due to the unlawful competitive acts of the rival players. In this case, I believe that the just verdict is to invoke the ex ante just rule of the game to the maximum extent and penalize the unjust acts of the rival players. In this case as well, I believe there is no reason to revise the ex ante just rule of the game. In the third and last stage, the defeat of the discontent player may be due to the fact that the ex ante just rule of the game in fact contains some flaws that were overlooked in the stage of designing and implementing the $e x$ ante just rule of the game. In this case, the ex ante just rule of the game, which is revealed to contain some ex post injustice, is in need for revision so as to re-design an ex ante just competitive game. In this case, the protest by the discontent player has a clear role of sending a signal that the ex ante just rule of the game should be revised in view of the ex post exposure of its flawed performance. This is an illustration of my current compounding of the consequentialist theory of justice and the procedural theory of justice.

WB \& MF: For many years, interpersonal comparisons of well-being were viewed with scepticism but it seems that attitudes have become more accepting with respect to this issue in recent years. What is your position on interpersonal comparisons and their use in social choice theory and welfare economics?

KS: There are two issues I would like to discuss in this context. The first issue is: What do we mean by interpersonal comparisons of well-being? The second issue is: Interpersonal comparisons of what?

To explain my stance on the first issue, consider the extended sympathy approach along the lines of Suppes (1966), Arrow (1963) and Sen (1970a, Chapter 9*). Let $x$ and $y$ be two conventionally defined social alternatives, and $i, j$ and $k$ be three individuals in the society. The pair $(x, i)$ denotes the situation of being in the position of individual $i$ when the social alternative $x$ prevails. Suppose that the individual $i$ prefers $(x, i)$ to $(y, i)$, viz., $i$ prefers $x$ to $y$, keeping his own personal identity whichever alternative in $\{x, y\}$ prevails in the society. Suppose now the preference of i over the pairs $(x, j)$ and $(y, k)$ is such that he prefers $(x, j)$ to $(y, k)$, viz., $i$ prefers being in the position of $j$ when $x$ prevails to being in the position of $k$ when $y$ prevails. This is still not an interpersonal comparison, but an intrapersonal and intersituational comparison. This approach allows the situation where $i$ prefers $(x, i)$ to $(y, i)$, and $j$ prefers $(y, i)$ to $(x, i)$, viz., $j$ has no sympathy to $i^{\prime}$ s preference for $x$ against $y$. Sen introduced his axiom of identity in the sense that $j^{\prime}$ s preference over the set of extended alternatives $\{(x, i),(y, i)\}$ should be in full concordance with $i^{\prime}$ s preference over the same set of extended alternatives $\{(x, i),(y, i)\}$. This is a sensible axiom to impose on intersituational comparisons, but a problem still remains. By the imposition of the axiom of identity, what started as intrapersonal and intersituational comparisons are turned into 
interpersonal comparisons. I am willing to accept this type of interpersonal comparisons. Indeed, I have made use of this conceptual framework in Suzumura (1978, 1981, 1983/2009, Chapter $6^{*}$, Chapter $9^{*}$, 1983a), where I tried to apply this framework to the problem of individual libertarian rights and also to the social-choice theoretic analysis of the fairness-as-no-envy concept. There are other approaches to interpersonal comparisons of utilities pursued in the literature, but I am not ready to accept, let alone endorse, these alternative approaches.

Let me turn to the second issue. When social choice theorists refer to the possibility of interpersonal comparisons, most if not literally all references are to interpersonal comparisons of utilities or welfares. However, there are contexts where the welfaristic informational basis can hardly support a meaningful analysis of the issue at stake. This is particularly so in the case of intergenerational welfare economics. Recollect a well-known passage from Henry Sidgwick (1874, p.414): "[I]t may be asked, How far we are to consider the interests of posterity when they seem to conflict with those of existing human beings? It seems ... clear that the time at which a man exists cannot affect the value of his happiness from a universal point of view; and that the interests of posterity must concern a Utilitarian as much as those of his contemporaries." The principle of equitable treatment of the present generation vis-à-vis the future generations, which is christened the Sidgwick equity principle, occupies a special niche in the literature on intergenerational justice. However, there is a serious problem. The generational utility stream up until the present is uniquely determined along the historical path, whereas the future evolution of human wellbeings cannot but be malleable in response to what choices the successive generations will make. This means that there is no way of knowing at present which path of the generational utility will materialize in the future. In view of this non-identity problem pointed out by Derek Parfit (1984), the problem of "intergenerational comparisons of what" cannot but surface in the context of intergenerational justice. Thus, the non-welfaristic informational basis such as the "primary social goods" à la John Rawls (1971) and the "functionings and capabilities" à la Amartya Sen (1985) becomes all the more relevant in the context of intergenerational justice.

WB \& MF: There is a recent development of studies that have to do with people's attitudes towards satisfaction and happiness in their lives. What is your view on this development? How should we, social choice theorists, incorporate these developments in our theories and in our framework?

KS: Normative economics is a slippery area and even a small step is valuable as long as it leads to a solid progress of our science. The so-called happiness studies are so much in vogue that it is all too natural to expect that the progress thereby made will lead to a resolution of many enigmas that are left unsettled by traditional approaches in normative economics. I am not well acquainted with the recent development of happiness studies, but I do wish them well in their pursuit for "instruments for the bettering of human life [Pigou (1920)]." As far as I can see, there are two agendas that decent happiness studies cannot but face up to: (i) to devise a method of calibration of individual human happiness; and (ii) to invent a method of amalgamating the calibrated human happiness indices into a social index for policy prescriptions. As far as the first agenda goes, my perception is that happiness studies already accomplished many contributions in close collaboration with the information and experience of experimental psychology and behavioral economics. However, more often than not, the happiness calibration is by means of locating human happiness on the closed unit interval [0,1], where 0 and 1 stand for the happiness in the "worst" and the "best" states of the world, respectively. Even after doing this, there still remains a problem of amalgamating individual happiness indices into a social index, where one cannot but face the conundrum of interpersonal comparisons all over again. I am unsure how the proponents of happiness studies cope with this second agenda, where many complications had to be faced by the practitioners of traditional normative economics. I sincerely wish them well.

WB \& MF: In addition to your work in social choice theory and welfare economics, which all our readers are familiar with, you have made contributions in other seemingly unrelated areas of economics, including industrial organization and the economic analysis of competition policy and industrial policy. Did this work emerge as the outcome of separate and independent projects or are there links to your work in our area?

KS: Among my work on industrial organization, let me cite two papers, viz., Suzumura and Kiyono (1987) and Suzumura (1992), to exemplify the interface between my work in this arena, on the one hand, and in the arena of welfare economics and social choice theory, on the other. Both papers are focused on the issue of welfare and competition, but by competition I do not mean an equilibrium concept such as the perfectly competitive state, where all strategic moves among rival firms are exhausted, but the process of competition through which rival firms struggle against each other in search for dominance 
in an existing market, or the acquisition of a new market.

It was in the early 1980s that I became aware of the lack of solid analysis of the welfare effects of competition in the process sense. I also recognized that there were two conventional beliefs persistently held side by side in Japan. The first belief, which had strenuously permeated through government officials in charge of industrial policy, a large portion of business representatives, and some ordinary citizens including senior academic economists, was under the strong influence of the Confucian maxim to the effect that "too much is as bad as too little." As a symbol of this conventional wisdom, a very strange expression of "excessive competition" had been widely in vogue. The second conventional belief had been held by younger generations of academic economists indoctrinated into the standard economic theory in the Western world. It embodies a belief in the role of competition as a decentralized mechanism for efficient allocation of resources. So strong was the contrast between these conventional beliefs that there were little, if any, interactions between people in the policy and business circle, on the one hand, and younger academic economists, on the other, concerning the welfare effects of competition. To construct a meaningful bridge between these conventional beliefs, my work started from what I christened the Baumol(1982, p.2) hypothesis to the effect that "the standard analysis [of industrial organization] leaves us with the impression that there is a rough continuum, in terms of desirability of industry performance, ranging from unregulated pure monopoly as the pessimal [sic] arrangement to perfect competition as the ideal, with relative efficiency in resource allocation increasing monotonically as the number of firms expands." To lend analytical substance to the Baumol hypothesis, a model of homogeneous oligopoly, where firms compete in terms of quantities, is used to define three crucial concepts. The first concept is the equilibrium number of firms $n_{e}$, where the equilibrium profits of Cournot competitors are exhausted through the entry/exit dynamics among potential firms and incumbent firms. The second concept is the first-best number of firms $n_{f}$, which maximizes the first-best market surplus. The third concept is the second-best number of firms $n_{s}$, where the second-best market surplus is maximized. Under suitable assumptions, which are not at all farfetched, it was shown by Suzumura and Kiyono (1987) that $n_{e}$ exceeds not only $n_{f}$, but also $n_{s}$. Thus, there is a sense, which is welfare-theoretic in nature, that competition may be construed to be socially excessive. These propositions, to be called excess entry theorems, are further generalized by Konishi, Okuno-Fujiwara and Suzumura (1990) in the presence of general equilibrium interactions among firms, and also by Okuno-Fujiwara and Suzumura (1993) in the presence of strategic R\&D commitment. In establishing these excess entry theorems, my purpose was not to provide a welfare-theoretic foundation for the first conventional belief, but to cast a reasoned and serious doubt on the welfaristic informational basis of normative economics. Indeed, the market surplus function in the case of partial equilibrium analysis, or the utility function of the representative consumer in the case of general equilibrium analysis, provides us with welfaristic information in full neglect of such non-welfaristic information as the equitable and anonymous treatment of market participants, or the role of competition as a discovery procedure in the sense of Friedrich Hayek. As I tried to expound in Suzumura (1999), the main message of the excess entry theorems is the need for a non-welfaristic informational basis of normative economics in the specific context of welfare and competition.

The second paper was also on welfare and competition, but the focal issue was the contrast between competition and collaboration. Even if firms compete fiercely in the product market, there may well be reasons for them to collaborate prior to the commencement of the product market competition. A good case in point is R\&D investment with a feature of club goods, which may result in cost-reducing innovation that is available for all firms that participate in the R\&D association. To be consistent with the competition law that stipulates that cartels are per se illegal, there should be a firm commitment by all firms participating in the R\&D association that they will compete in the product market along with outsider firms. Is the formation of such a R\&D association welfare improving vis-à-vis competition in the R\&D market as well as in the product market? The purpose of Suzumura (1992) was to identify the condition under which the R\&D association may perform better than the competitive R\&D commitment. This analysis was meant to clarify the balance between non-cooperative activities and cooperative activities in the two-stage game of commitment and competition. In this sense, it is a pilot study of welfare-theoretic analysis of competition and collaboration. I believe that the relevance of this work in the research program of normative economics should be clear.

WB \& MF: You mentioned your involvement in actual policy making and issues involving competition. Do you have the impression that policy makers are open to what we have to offer in terms of implementing the results obtained in social choice theory?

KS: Let me answer your question by relating a bad experience and a good experience I encountered in Japan. The bad experience relates to a deliberation council on telecommunications reform, which took place in the mid-1980s. The government officials in charge of this deliberation council were so self-assured 
that they started with the premise that sagacious regulations led by the top government officials will always perform better than leaving things to spontaneous competition as much as possible. They were also quite chauvinistic and unwilling to examine experiences accumulated in foreign countries, let alone to learn a lesson from insightful regulatory reforms in the UK and the US. Indeed, the timing of this telecommunications reform in Japan was in conformity with the introduction of the so-called incentive regulation in the US. I was naïve enough to ask government officials what we could learn from the US experience of incentive regulation and received no answer whatsoever. Indeed, they responded as if nothing called incentive regulation ever existed. Soon afterwards, my term of service in the telecommunications deliberation council expired, which was never renewed. Thus, my first experience of being involved in the government decision-making process was futile, fruitless and frustrating. Since the purpose of deliberation councils is to design an economic policy or an economic mechanism for helping politicians to make the official public decision, I must say that I had no chance to influence the government decision at all. I should also add that there was very little room for social choice theorists to apply their theoretical results to actual policy issues.

The good experience is that I was invited to lead the inauguration of the Competition Policy Research Center (CPRC) within the Fair Trade Commission of Japan (JFTC), which partly occupied my time and energy from 2003 to 2008. The factual background of this invitation was the two joint research projects that I organized in the early 1980s on Japanese industrial policy and on Japanese competition policy toward the end of the 1990s. The outcomes of these projects were subsequently published as Industrial Policy of Japan [Komiya, Okuno and Suzumura (1988)] and Competition Policy of Japan [Goto and Suzumura (1999)], respectively. Before the inauguration of CPRC, JFTC was predominantly an organization of legal experts with little, if any, systematic help from economic analysis. During my directorship over five years, I believe I had kicked off the tradition of economic analysis that might provide the information needed for legal decisions to be made by JFTC.

Although I found this experience intellectually pleasing, I should mention two important reservations. In the first place, the legal decisions by JFTC are within the exclusive jurisdiction of five commissioners, who are appointed by the national diet. This being the case, there is no channel through which CPRC can exert direct influence on competition policy decisions. However, this does not exclude the possibility that CPRC exerts indirect influence on competition policy decisions through the provision of information based on economic analyses. In the second place, there is a possibility that CPRC may help the new design and implementation of the legal framework of competition policy. A good case in point is the revision of competition law in 2005. One of the focal issues of this revision was the introduction of an institutional device for improving the performance of the surcharge system, which was introduced in 1977 in order to keep cartels and illegal agreements among competitive bidders under due control. The option actually proposed and implemented was the leniency scheme to the effect that those members of the cartels and/or illegal agreements who submit the information about the anti-competitive acts in question to the competition policy authority would be exempted from a substantial portion of surcharge that would otherwise be imposed, thereby introducing strong incentives for the members of the anticompetitive acts to comply "voluntarily" with the competition policy initiatives. This scheme was in actual use in other parts of the world, which was transplanted into Japan in 2005. If there were no such device ready for transplantation from outside, there would be a golden opportunity for CPRC to design and propose a novel mechanism for the competition policy authority to examine and implement. In principle, therefore, there is a potential room for social choice theory to contribute to the institutional reforms in actual policy contexts.

WB \& MF: What advice would you give to your younger colleagues in that respect? Should they try to get more involved? What ways should they use to be more influential?

KS: I don't think that there is a universally applicable advice in this arena. A sensible advice seems to be contingent on the young scholar's own view on the mission of social sciences. If one has the strong conviction that a social scientist should aspire to drafting his/her own prescription for bettering human lives, it is advisable to know much about actual procedures for society-wide decision-making, and think about how his/her scientific research can influence these procedures in actual use. Please don't take me wrong. I am not saying that he/she should switch his/her life from sciences to politics or bureaucracies; I am saying that he/she should be vigilant enough and be ready to propose timely and through effective channels his/her prescription for bettering human lives. If he/she is willing to make frequent roundtrips between theory and practice in this sense, he/she will be richly remunerated by an abundant agenda for far-sighted investigations. One should be warned that this route requires a lot of investment of one's time as well as energy. I confess that I myself have sacrificed a lot of time and energy for my firm commitment to the vistas opened up by Pigou and his intellectual descendants, but I have no reason to 
regret my deliberate choice.

If, on the other hand, one is better suited for pursuing purely theoretical work in welfare economics and social choice theory, I have nothing to say against such a pursuit. To concentrate on the basic research of purely theoretical nature is a choice that is open only for rare species among social scientists. I wish them well, and hope that their theoretical work will shed new light on our research agenda for normative economics in the future.

WB \& MF: This gives us a good idea about the position of our discipline in the outside world, but what about our position within economics, within the academic community? You have been involved both in our Society and in our journal from the very beginning. What do you see as the challenges we are going to face as a group in the future? Would you say that it has become more difficult for social choice theorists to be appreciated within the economics profession in general, and within economic theory in particular? How do you view the attitude of economics journals toward contributions in social choice theory? Do you perceive there to be a bias against our field?

KS: Let us remind ourselves of the monumental World Meeting on Social Choice Theory held in the summer of 1980. Most of the active social choice theorists in those days gathered in Caen and talked about the inauguration of the Society for Social Choice and Welfare and the commencement of a new journal to be called Social Choice and Welfare. I recollect that the first proposal did not cause any serious objection, and the Society for Social Choice and Welfare made a start with the first president, Kenneth Arrow, who was unanimously elected by the founding members of the Society. It was on the second issue that the members had serious differences of opinion. As a background of this difference, there were strong hostilities on the part of academic journals towards social choice theory. Indeed, an announcement was made in the top journal to the effect that the papers in social choice theory were in excess supply and would be treated differently from the papers in other fields of research. I thought at that time and I still think now that this editorial decision was wrong and unjust to the researches in the field of social choice theory. Many founding members of the Society seem to have thought similarly, and most of them argued that we should commence a journal of our own for the sake of securing a proper outlet of our research outcomes. The counterargument, which was expressed by some of the founding members including myself, emphasized that the biased treatment of social choice theory should not be taken as a legitimate reason to start our specialized journal, as it would strengthen the reason to treat social choice theory unfavourably by enabling the editors to suggest to the authors to try the specialized journal of their own rather than the mainstream journals that are under severe space limitations.

I am keenly aware that Social Choice and Welfare has made great contributions to the promotion of our field of research, but I still retain my view at that time to some extent. It is my strong belief that we should not confine ourselves to a self-built sanctuary. I believe that most of the top researchers in our field of research are revealing their preference, which is largely in conformity with my view. It seems to me that this is the sure-fire choice for social choice theorists to be appreciated within the economics profession in general, and within economic theory in particular.

WB \& MF: What do you view as the major accomplishments in social choice theory and welfare economics in the recent past? Where do you see our field going?

KS: To prepare for my answer to your first question, let me briefly refer back to Jeremy Bentham and Arthur Pigou. According to the standard understanding of the research program of Pigou's "old" welfare economics, which is founded on the Benthamite utilitarianism, the major scenario of welfare economics may be captured as follows: Design an institutional framework of a society with $n$ individuals, where $2 \leq n<+\infty$, so as to implement the solution $x^{B P} \in S$ to the following constrained maximization program:

$$
\operatorname{Max}\left\{u_{1}(x)+u_{2}(x)+\cdots+u_{n}(x)\right\} \text { over all } x \in S,
$$

where $u_{i}$ is the utility function of individual $i \in N:=\{1,2, \ldots, n\}$ and $S$ is the set of feasible alternatives. ${ }^{14}$ The research program of the social welfare function school of "new" welfare economics a la Abram Bergson and Paul Samuelson may be captured as follows: Design an institutional framework of a society so as to implement the solution $x^{B S} \in S$ to the following constrained maximization program:

$$
\operatorname{Max} f\left(u_{1}(x), u_{2}(x), \cdots, u_{n}(x)\right) \text { over all } x \in S,
$$

\footnotetext{
${ }^{14} \mathrm{~B}-\mathrm{P}$ is the abbreviation of Bentham and Pigou.
} 
where $f$ denote denotes a Bergson-Samuelson social welfare function. ${ }^{15}$

Observe that both (B-P) and (B-S) capture the essence of mainstream welfare economics in the constrained maximization paradigm. This simple fact helps us to identify two eminent developments in welfare economics and social choice theory.

The first development I want to identify and evaluate is the theory of implementation due to Leonid Hurwicz $(1972,2008)$ and Eric Maskin $(1977 / 1999,2008)$. The gist of this approach is to design a game form such that the set of equilibrium outcomes of the game coincides with the set of solutions to the constrained maximization problem (B-S) for each and every profile of individual utility functions and given the equilibrium concept prevailing in the society. It is worthwhile to recollect that Arrow $(1951 / 1963$, p.7) observed that "[e]ven in a case where it is possible to construct a procedure showing how to aggregate individual tastes into a consistent social preference pattern, there still remains the problem of devising rules of the game so that individuals will actually express their true tastes even when they are acting rationally." The Hurwicz-Maskin theory of implementation may be construed to be an answer to the problem posed by Arrow. One may even dare to say that the Hurwicz-Maskin theory is the first formulation of the Benthamite program of social reform in the form of (B-S). Starting from the seminal contributions due to Hurwicz $(1972,2008)$ and Maskin $(1977 / 1999,2008)$, the theory of implementation became the first major field of research in social choice theory since Arrow kicked off the axiomatic study on the formation of a social objective through the democratic aggregation of individual preference orderings.

The second development I want to identify and evaluate is also related to the maximization problems (B-P) and (B-S), but the exact nature of this relationship is less direct and more critical than in the case of the first development. It is also more philosophical in nature and may be thought to go squarely against the standard scenario of normative economics. The point of departure is the identification of the two schools of thought within normative economics. The first school identifies the major task of welfare economics to be the design of an institutional framework of a society for the sake of implementing the socially best consequences from the set of feasible alternatives. The second school originates in the "old" welfare economics a la Pigou. Instead of focusing on the implementation of the socially best alternative as in the case of the first school, the second school aspires for the improvement of social welfare by designing the instrument for the bettering of human life. In my own perception, the contrast between these two schools of welfare economics can be traced back to Amartya Sen's (2009) monumental treatise of a philosophical nature, which called our attention to the sharp contrast between transcendental institutionalism and the comparative assessment approach. Much juice is to be extracted in this broad arena, and I am looking forward to the exploration of the avenue that was opened by Sen. ${ }^{16}$

Where do I see our field going? I am not in a position of predicting the future course of evolution. The best I can do is to express my personal desire for the future evolution of welfare economics and social choice theory. To begin with, I hope that much more effort will be devoted to the procedural aspects of normative economics, thereby enriching our understanding on the pros and cons of non-consequentialist approaches. I also hope that there will be further explorations of intergenerational aspects of normative economics. Beginning with the insightful observation by Sidgwick (1874), many scholars in normative economics and moral philosophy have explored the logical consequences of treating different generations equitably. Concerning the logical compatibility between the Sidgwickean equity principle and the Pareto efficiency principle, social choice theorists have elaborated the impossibility theorem by Peter Diamond (1965). ${ }^{17}$ It is also worthwhile to mention the intriguing concept of sustainable development, which was introduced in 1980 by the International Union for the Conservation of Nature and Natural Resources and acquired worldwide recognition by means of the Brundland Report [World Commission on Environment and Development (1987)]. It is clear that this concept echoes the Sidgwickean equity principle, but the exact analysis still awaits future exploration. Another good case in point is the problem of global warming, the proper analysis of which forces us to confront the non-identity problem due to Derek Parfit (1984). It is my strong desire that the concerted efforts by normative economists and philosophers will shed clear light on these crucial problems in the future.

WB \& MF: You retired from Waseda University at the end of March 2014 after six years of teaching social choice theory and public philosophy. Your Valedictory Lecture was delivered under the title: "In Search for Welfare Economics with Red Corpuscles." Would you explain what you intended to convey to your audience by choosing this rather unusual title?

\footnotetext{
${ }^{15} \mathrm{~B}-\mathrm{S}$ is the abbreviation of Bergson and Samuelson.

${ }^{16}$ This issue is discussed more in detail in Chapter 28 of Suzumura (forthcoming).

${ }^{17}$ On some aspects of this development, see Roemer and Suzumura (2007). See also Bossert and Suzumura (2010, Chapter 10) for Suzumura's own work in this arena.
} 
KS: In his touching tribute to James Meade at his eightieth birthday, Robert Solow (1987, p.986) wrote as follows: "I suppose Meade's effort could be described as fundamental welfare economics, but welfare economics with red corpuscles, not the sort of attenuated theory that concludes that if only everything were convex and everybody knew everything and there were perfect markets for all future contingent commodities, including contingencies for which no vocabulary now exists, then with costless lump-sum transfers we could make all for the best in this best of imaginable worlds. Meade expects welfare economics to provide advice, not resignation." In my perception, this characterization of Meade's work brings us all the way back to Pigou's Preface to The Economics of Welfare. It was in search for the resurgence of welfare economics in the spirit of Pigou and Meade that I borrowed this unorthodox circumlocution from Solow.

I am convinced that the best aspect of retirement is that one can exercise the full freedom of choice to devote oneself to the research activities of one's strongest concern. I am impatient to kick off my own game of welfare economics with red corpuscles. 


\section{Reference}

Arrow, K. J. (1951; second edition 1963), Social Choice and Individual Values, Wiley, New York.

Arrow, K. J. (1959), "Rational choice functions and orderings," Economica 26, 121-127.

Arrow, K. J. (1987), "Arrow's theorem," in: J. Eatwell, M. Milgate and P. Newman, eds., The New Palgrave: A Dictionary of Economics, $1^{\text {st }}$ vol., Macmillan, London, 124-126.

Arrow, K. J., A. K. Sen and K. Suzumura (2002; 2011), Handbook of Social Choice and Welfare, North-Holland/Elsevier, Amsterdam, $1^{\text {st }}$ vol., 2002; $2^{\text {nd }}$ vol., 2011.

Austen-Smith, D. (1982), "Restricted Pareto and rights," Journal of Economic Theory 10, 89-99.

Baumol, W. J. (1982), "Contestable markets: An uprising in the theory of industrial structure," American Economic Review 72, 1-15.

Bentham, J. (1789), An Introduction to the Principles of Morals and Legislation, Payne, London. Republished in 1907 by Clarendon Press, Oxford.

Bentham, J. (1843), "Anarchical fallacies." First published in English in: J. Bowring, ed., The Works of Jeremy Bentham, Vol. II, William Tait, Edinburgh, 489-534.

Berlin, I. (1958), Two Concepts of Liberty, Oxford University Press, Oxford.

Bossert, W. (2008), "Suzumura consistency," in P. K. Pattanaik, K. Tadenuma, Y. Xu and N. Yoshihara, eds., Rational Choice and Social Welfare: Theory and Applications, Springer, Berlin, 159-179.

Bossert, W., Y. Sprumont, and K. Suzumura (2005), "Consistent rationalizability," Economica 72, 185-200.

Bossert, W. and K. Suzumura (2010), Consistency, Choice, and Rationality, Harvard University Press, Cambridge, Mass.

Champernowne, D. G. (1969), Uncertainty and Estimation in Economics, Vol. I, Holden-Day, San Francisco.

Diamond, P. (1965), "The evaluation of infinite utility streams," Econometrica 33, 170-177.

Gaertner, W., P. K. Pattanaik and K. Suzumura (1992), "Individual rights revisited," Economica $59,161-177$.

Gibbard, A. (1974), "A Pareto-consistent libertarian claim," Journal of Economic Theory 7, 388410 .

Goto, A. and K. Suzumura, eds. (1999), Competition Policy of Japan, The University of Tokyo Press, Tokyo. In Japanese.

Hansson, B. (1968), "Choice structures and preference relations," Synthese 18, 433-458.

Hayek, F. A., ed., (1935), Collectivist Economic Planning, Routledge, Cambridge, UK.

Hegel, G. W. F. (1991), Elements of the Philosophy of Right, Cambridge Texts in the History of Political Thought, edited by Allen W. Wood, Cambridge University Press, Cambridge, UK.

Hicks, J. (1981), Wealth and Welfare, Collected Essays on Economic Theory, Vol. I, Basil Blackwell, Oxford.

Houthakker, H. S. (1950), "Revealed preference and the utility function," Economica 17, 159-174.

Hurwicz, L. (1972), "On informationally decentralized systems," in C. B. McGuire and R. Radner, eds., Decision and Organization, North-Holland, Amsterdam, 297-336.

Hurwicz, L. (2008), "But who will guard the guardians?" American Economic Review 98, 577-585.

Kelly, J. S. (1987), "An interview with Kenneth Arrow," Social Choice and Welfare 4, 43-62. 
Kolm, S.-Ch. (1972/1997), Justice et Equité, Editions du Centre National de la Recherche Scientifique, Paris. English translation: Justice and Equity, The MIT Press, Cambridge, Mass.

Kolm, S.-Ch. (1996), Modern Theories of Justice, The MIT Press, Cambridge, Mass.

Komiya, R., M. Okuno, and K. Suzumura, eds. (1988), Industrial Policy of Japan, Academic Press, San Diego.

Konishi, H., M. Okuno-Fujiwara and K. Suzumura (1990), "Oligopolistic competition and economic welfare: A general equilibrium analysis of entry regulation and tax-subsidy schemes," Journal of Public Economics 42, 67-88.

Mas-Colell, A. (1982), "Revealed preference after Samuelson," in: G. R. Feiwel, ed., Samuelson and Neoclassical Economics, Kluwer, Amsterdam, 72-82.

Maskin, E. (1977/1999), "Nash equilibrium and welfare optimality" Review of Economic Studies 66, 1999, 23-38. Originally circulated as MIT Working Paper in 1977.

Maskin, E. (2008), "Mechanism design: How to implement social goals," American Economic Review $98,567-576$.

Mishan, E. J. (1960), “A survey of welfare economics, 1939-59," Economic Journal 70, 197-257.

Negishi, T. (1972), General Equilibrium Theory and International Trade, North-Holland, Amsterdam.

Nikaido, H. (1970), Introduction to Sets and Mappings in Modern Economics, North-Holland, Amsterdam.

Nozick, R. (1974), Anarchy, State and Utopia, Basil Blackwell, Oxford.

Okuno-Fujiwara, M. and K. Suzumura (1993), "Symmetric oligopoly and economic welfare: A synthesis," Economic Theory 3, 43-59.

Parfit, D. (1984), Reasons and Persons, Oxford University Press, Oxford.

Pigou, A. C. (1920), The Economics of Welfare, Macmillan, London.

Rawls, J. (1971), A Theory of Justice, Harvard University Press, Cambridge, Mass.

Richter, M. K. (1966), "Revealed preference theory," Econometrica 34, 635-645.

Robbins, L. (1932), An Essay on the Nature and Significance of Economic Science, Macmillan, London.

Roemer, J. and K. Suzumura, eds. (2007), Intergenerational Equity and Sustainability, Elsevier, Amsterdam.

Samuelson, P. A. (1938), "A note on the pure theory of consumer's behaviour," Economica 5, 61-71.

Samuelson, P. A. (1947), Foundations of Economic Analysis, Harvard University Press, Cambridge, Mass.

Samuelson, P. A. (1948), "Consumption theory in terms of revealed preference," Economica 15, 243-253.

Samuelson, P. A. (1950), "The problem of integrability in utility theory," Economica 17, 355-385.

Sen, A. K. (1969), "Quasi-transitivity, rational choice and collective decisions," Review of Economic Studies 36, 381-393.

Sen, A. K. (1970), "The impossibility of a Paretian liberal," Journal of Political Economy 78, 152-157.

Sen, A. K. (1970a), Collective Choice and Social Welfare, Holden-Day, San Francisco.

Sen, A. K. (1971), "Choice functions and revealed preference," Review of Economic Studies 38, 307-317. 
Sen, A. K. (1976): "Liberty, unanimity and rights," Economica 43, 217-245.

Sen, A. K. (1985), Commodities and Capabilities, Elsevier, Amsterdam.

Sen, A. K. (1992), "Minimal liberty," Economica 59, 139-159.

Sen, A. K. (1993), "Internal consistency of choice," Econometrica 61, 495-521.

Sen, A. K. (2009), The Idea of Justice, Harvard University Press, Cambridge, UK.

Sidgwick, H. (1874), The Methods of Ethics. The $7^{\text {th }}$ edn., Macmillan, London, 1907.

Solow, R. M. (1987), "James Meade at eighty," Economic Journal 97, 986-988.

Sugden, R. (1985), "Liberty, preference and choice," Economics and Philosophy 1, 185-205.

Suppes, P. (1966), "Some formal models of grading principles," Synthese 6, 284-306.

Suzumura, K. (1976), "Rational choice and revealed preference," Review of Economic Studies 43, 149-158.

Suzumura, K. (1976a), "Remarks on the theory of collective choice," Economica 43, 381-390.

Suzumura, K. (1977), "Houthakker's axiom in the theory of rational choice," Journal of Economic Theory 14, 284-290.

Suzumura, K. (1978), "On the consistency of libertarian claims," Review of Economic Studies 45, 329-342.

Suzumura, K. (1981), "On Pareto-efficiency and the no-envy concept of equity," Journal of Economic Theory 25, 367-379.

Suzumura, K. (1983/2009), Rational Choice, Collective Decisions, and Social Welfare, Cambridge University Press, New York, first ed., 1983; Paperback edition, 2009.

Suzumura, K. (1983a), "Resolving conflicting views of justice in social choice," in: P. K. Pattanaik and M. Salles, eds., Social Choice and Welfare. North-Holland, Amsterdam, 125-149.

Suzumura, K. (1992), "Cooperative and noncooperative R\&D in oligopoly with spillovers," American Economic Review 82, 1307-1320.

Suzumura, K. (1999), "Consequences, opportunities and procedures," Social Choice and Welfare $16,17-40$.

Suzumura, K. (1999a), "Report on the far eastern activities of the Econometric Society," Econometrica $67,221-233$.

Suzumura, K. (2000), "Welfare economics beyond welfarist-consequentialism," Japanese Economic Review 51, 1-32.

Suzumura, K. (2011): "Welfarism, individual rights, and procedural fairness," in: K. J. Arrow, A. K. Sen and K. Suzumura, eds., Handbook of Social Choice and Welfare, Vol.II, Elsevier, Amsterdam, 605-685.

Suzumura, K. (forthcoming), Consequences, Opportunities, and Procedures: Selected Papers on Social Choice and Welfare, Harvard University Press, Cambridge, Mass.

Suzumura, K. and K. Kiyono (1987), "Entry barriers and economic welfare," Review of Economic Studies 54, 157-167.

Suzumura, K. and Y. Xu (2001), "Characterizations of consequentialism and non-consequentialism," Journal of Economic Theory 101, 423-436.

Suzumura, K. and Y. Xu (2003), "Consequences, opportunities, and generalized consequentialism and non-consequentialism," Journal of Economic Theory 111, 293-304.

Suzumura, K. and Y. Xu (2004), "Welfarist-consequentialism, similarity of attitudes, and Arrow's general impossibility theorem," Social Choice and Welfare 22, 237-251. 
Szpilrajn, E. (1930), "Sur l'extension de l'ordre partiel," Fundamenta Mathematicae 16, 386-389.

Tadenuma, K. (2002), "Efficiency first or equity first: Two principles and rationality of social choice," Journal of Economic Theory 104, 462-472.

Varian, H. R. (1974), "Equity, envy and efficiency," Journal of Economic Theory 9, 61-91.

Varian, H. R. (1975), "Distributive justice, welfare economics, and the theory of fairness," Philosophy and Public Affairs 4, 223-247.

World Commission on Environment and Development (1987), Our Common Future, Oxford University Press, Oxford. 